Research Article

\title{
Collaborative Product Portfolio Design Based on the Approach of Multichoice Goal Programming
}

\author{
Sheng-Yuan Wang $\mathbb{D}^{1,2}$ Wan-Ming Chen, ${ }^{1}$ and Ying Liu ${ }^{2}$ \\ ${ }^{1}$ College of Economics and Management, Nanjing University of Aeronautics and Astronautics, Nanjing, Jiangsu 210016, China \\ ${ }^{2}$ Business School, Nanjing Xiaozhuang University, Nanjing, Jiangsu 211171, China \\ Correspondence should be addressed to Sheng-Yuan Wang; 56439976@qq.com
}

Received 30 October 2020; Revised 23 December 2020; Accepted 30 December 2020; Published 8 January 2021

Academic Editor: Bekir Sahin

Copyright ( $) 2021$ Sheng-Yuan Wang et al. This is an open access article distributed under the Creative Commons Attribution License, which permits unrestricted use, distribution, and reproduction in any medium, provided the original work is properly cited.

\begin{abstract}
Product portfolio optimization is a typical multiobjective problem. The multichoice goal programming method becomes a popular means of resolving multiobjective decision problems. However, the classic multichoice goal programming method treats the product portfolio optimization in isolation and does not consider the mutual influence between portfolio products. Researchers should consider the interaction between products in portfolio optimization so that they can be adjusted to "real world" problems. The interaction between products can be explained by population dynamics. Logistic model is a classical method to analyze the population interaction. The equilibrium point of logistic model can show the ideal state of product population coordinated development. The combination of logistic and multichoice goal programming method is an effective approach to analyze the interaction of product portfolio. This paper therefore proposes a new alternative method to formulate the multiobjective problem and also uses an illustrative example to demonstrate the usefulness of the proposed method. The comparative analysis of model optimization results shows that logistic multichoice goal programming model can take into account resource constraints, product collaboration, and output maximization. Logistic multichoice goal programming model shows good performance in the aspects of operation complexity, operation time, sensitivity analysis, and collaborative entropy evaluation.
\end{abstract}

\section{Introduction}

It is established that decision-making affects organizational performance. Companies can therefore achieve greater profits by increasing revenue or reducing costs. In practice, company decision-making is a complicated process because many decision-related problems involve multiple criteria or conflicting objectives. GP (goal programming) has been widely used to resolve multiple criteria or the objective optimization problem. The rationale behind the application of GP is that the decision maker will outline aspiration levels that are closely tied to resource limitations.

Researchers will sometimes encounter more complex decision-making issues than increasing revenue and reducing cost. For example, research objects are symbiotically related and researchers should consider the relationship between research objects when making decisions. For example, consider product portfolio optimization. Suppose that a company is manufacturing and launching products $x_{1}$ and $x_{2}$ and then imagine the following scenarios: (1) the company adopts a specialized strategy. Products $x_{1}$ and $x_{2}$ are different models of the same product. One example is the competition between Ford Motor's Mondeo and Taurus models. (2) The company adopts a related diversification strategy. The relationship between the two products is mainly collaborative. One example would be a special purpose drone and the drone's operation simulator. There is a synergistic relationship between the two, and when more drones are sold, market demand for simulators increases. The sale of simulators and their applications promotes the sale of special drones. (3) The company adopts an unrelated diversification strategy. Two products share company resources, and their relationship is mainly competitive. One example is a company that produces mobile phone batteries and petrol cars. 
Product portfolio research needs to consider synergy or competition between products. To solve similar problems, this paper views research objects as symbiotic populations and introduces the dynamic mechanism of symbiotic population. This paper is also practically significant because it provides an appropriate analysis method for various products, which companies can then use to analyze and plan the development of PPs (product populations). The PPs need to be kept to an adequate scale in order to promote the development of collaborative relationships in the population. This approach can analyze the state of development of the current PP (product population) and help to determine if it is in a collaborative state. The intrapopulation relationship shows the level of competition in this industry. The direction of this field's development can be determined by referring to the results of the analysis. Companies can use this method to study industrial policies, and this can in turn help them to create appropriate policies that promote the development of PPs.

The research organization of this article is as follows: this paper (1) reviewed the progress of related research through literature review, (2) used population dynamics to analyze the influence mechanism between interactive product populations, and (3) built multichoice goal programming and logistic multichoice goal programming models for product portfolio optimization and comparative analysis. This paper proposed an alternative method to formulate multiple choices and, in so doing, made three contributions: (1) it constructed interactive relationships between products on the basis of population dynamics and logistic models; (2) it embedded interaction constraints in the multichoice goal programming model and thereby enhanced product collaborative optimization capabilities; and (3) it demonstrated how the logistic-multichoice goal programming approach can be easily used to solve interaction issues between products in product portfolio optimization.

The highlights of this article are as follows: (1) from the perspective of population dynamics, the problem of product portfolio optimization is analyzed, which expands the application scenarios of the logistic model. (2) The equilibrium point characteristics of population growth analysis are extended to the multichoice goal programming model, which expands the analysis function of the multichoice goal programming model.

\section{Literature Review}

A company's product portfolio management seeks to use priority resources to achieve goals, maximize the value of the product portfolio, and achieve the correct combination of programs [1]. Related applied research has provided further insight. Bayou and Reinstein summarize the important role of a fuzzy hierarchical model in the adjustment of a product portfolio strategy [2]. Chung and Pearn use analytic hierarchy process and the Network Analysis Method to analyze the semiconductor production process and obtain the best product combination [3]. Rao draws on empirical research and analysis of pharmaceuticals to verify the important role of product portfolio management in the process of corporate strategic adjustment [4]. A substantial amount of research has engaged product portfolio decisions. The main methods that have been used include linear programming, ActivityBased Costing, Intelligent Algorithm, TOC (Theory of Constraints) method, and a comprehensive algorithm that combines each of these methods. Of these, the TOC method, which was first proposed by Goldratt [5], is the most frequently used. Luebbe and Finch suggest that a combination of TOC and integer linear programming method can produce the optimal product portfolio [6]. The TOC method has continuously improved. Tanhaei and Nahavandi proposed a heuristic algorithm to determine the optimal product portfolio in two resource-constrained environments [7]. Besides, Kahveci et al. apply TOC to companies with capacity constraints [8]. The TOC method mainly considers resource constraints, and it is therefore difficult for this paper to meet its research needs. With the development of related studies, more studies have used a composite approach to discuss product (stock/project) portfolio selection. Bhattacharyya et al. introduced a novice solution methodology for multiobjective optimization problems having the coefficients in the form of uncertain variables [9]. The embedding theorem established the set of uncertain variables that can be embedded into the Banach space. Bhattacharyya et al. resented a fuzzy multiobjective programming approach to facilitate decision-making in the selection of R\&D projects [10]. Guo et al. considered a fuzzy multiperiod portfolio selection problem with V-shaped transaction cost [11]. A mean-variance model is formulated with the objective of maximizing the terminal return under the total risk constraint over the whole investment. Debnath et al. apply a hybrid multiple criteria decision-making approach for strategic project portfolio selection of agro byproducts [12]. The method is applied to rank the strategic project portfolios according to the aggregated preferences of decision-makers. Mohuya et al. provided a cross-entropy based multiobjective uncertain portfolio selection approach [13]. A multiobjective uncertain portfolio selection model has been proposed by defining average return as expected value, risk as variance, and divergence among security returns as cross-entropy where the security returns are considered as uncertain variables. Kar et al. proposed a new biobjective fuzzy portfolio selection mode to choose portfolio [14]. It can be seen that research papers can embed constraints in traditional optimization models according to the research objectives. At present, optimization models that consider the synergy between products are relatively rare. This paper will therefore develop a comprehensive optimization method that encompasses resource constraints, output maximization, and population coordination.

A population is a group of individuals from the same species who collectively occupy a specific time and space. A "population" of products addresses the same pan-customer group, and the different parts are conjoined by relationships of mutual influence. The ecological population model can be used to study the characteristics of the product portfolio, and the portfolio products are known as the "PPs" (product populations). In recent years, ecology has been widely applied in different fields. Most of the literature 
on product management applications focuses on optimizing enterprise product portfolio scale and structure, although a few authors also consider factors that affect product evolution. Rober observes that the degree of difference in consumer preferences, the cost of product development, and the product's marginal revenue are the main factors that determine the product line's width and length [15]. Fruchter et al. introduce a genetic algorithm to explore the cannibalization of product items and resolve the optimization of the product line under relevant conditions [16]. Ommering puts forward the concept of product population to resolve the diversity and versatility of the software product development process [17], and quickly completes the software product upgrade and evolution by applying software architecture and reorganizing and splitting modules. Kazuhiko et al. take the impact of the number of air conditioners in Japan on climate warming as an example [18] and use an integrated life cycle assessment and population balance model to evaluate the impact that the social scale of product populations has on the environment. Kim et al. use a population balance model to consider the life cycle and evaluate the waste of South Korean electronics and electronic equipment [19]. Most of the current literature uses ecological population theory and methods to study the coevolution of corporate and industrial populations, but its application remains restricted to the macro and meso levels. Few product portfolio contributions consider the micro level of the enterprise in great depth. There is no detailed account of how the enterprise achieves and maintains balance, and there is also no extensive consideration of the product portfolio strategy that the enterprise should formulate.

By drawing on the Theory of Population Dynamics, this paper considers a company's product portfolio as a product population and explores how the product population's structure and scale can be determined under conditions of population synergy. It also considers how the product population's scale and structure can be continuously optimized in a way that balances enterprise output, product synergy, and resource allocation. To solve these conundrums, this paper maintains that researchers need to: (1) define the relationship between products by conducting qualitative research on the product portfolios, (2) use the logistic model to analyze the product population's growth balance and determine the relationship between related parameters, (3) use the parameter relationship to modify the MCGP (multichoice goal programming) model, and (4) use the logistic-MCGP model for combination and scale optimization. Researchers will then evaluate the optimization results.

\section{Product Population Growth Model}

In this section, researchers introduce the construction ideas of the product population growth model. Based on the logistic model, an enterprise product population relationship model is proposed, and the equilibrium point is analyzed. At last, the model is explained with a real-life scenario.
3.1. Model Construction Ideas. When there are abundant resources, populations can grow at geometric or exponential rates. As resources deplete, population growth rate slows and eventually stops. This is known as logistic population growth. The environment limits population growth by changing birth and death rates. On average, small organisms experience per capita increases at higher rates and more variable populations; large organisms, in contrast, have lower per capita increase rates and less variable populations.

Once the resource constraints and the need for specialization are taken into account, it becomes apparent that it is difficult for any firm to develop all types of products. The study of PP dynamics should consider the influence of resource constraints. A population's ecological sense is a collection of certain organisms within a given time and space. The region where the population grows is a relatively homogeneous nonlinear region that is different from the surrounding environment. Within natural hierarchy systems, there are universal temporal and spatial constraints.

The spatial distribution characteristics of different ecological regions (including boundary, distance, nature, shape, and size) generate ecological zones, form the differences of ecosystem, and regulate population growth. The model of enterprise PP dynamics focuses on the quantity change in the PP. Its changing rule is based on the nonlinear growth principle of biological population quantity. Most species have a nonlinear growth model.

Competition and synergy within populations are also important and are based on the intraspecific competition principle of biological populations. Competition exists within the biological population. When the population scale is larger, the competition is more intense. Competition among populations performs the function of population size adjustment. There is also a certain competition mechanism in the PPs that will suppress their excessive expansion to some extent.

Intraspecific competition is also part of the "survival of the fittest" and it should therefore be an important component of the growth model for PPs. There is also a competitive or synergistic relationship between the different PPs. In citing the preceding points, this study uses the Growth Dynamics Model of Biological Population Theory to investigate the development characteristics of PPs.

3.2. Model Deduction. In accordance with the logistic model, this paper constructs an internal relationship model of $\mathrm{PP}_{1}$ (product population 1). It follows that

$$
G_{1}(t)=\frac{\mathrm{d} N_{1}(t)}{\mathrm{d} t}=\alpha_{1} N_{1}\left(1-\frac{N_{1}}{M_{1}}\right),
$$

where $G_{1}(t)$ indicates the population growth rate of phase $t$ and $N_{1}(t)$ indicates the number of individuals in the population in phase $t$. In a certain period of time (phase $t$ ), $K_{1}$ is the maximum population scale in a constant environment. Each unit occupies resources and is defined as $1 / M_{1}, \alpha_{1}$ reflects the promotion of population growth. (1$\left(N_{1} / M_{1}\right)$ ) reflects retarded growth caused by the population's consumption of limited resources. 
If $G_{1}(t)>0$, then $\Delta N_{1}(t)>0$. The synergistic effects are the dominant effects in the population. Enterprise resources can support an increase in the number of individuals in an $\mathrm{PP}$, which means the growth can be sustainable.

If $G_{1}(t)<0$, then $\Delta N_{1}(t)<0$ and the competition effect is dominant in the population. Resources are less able to support an increase in the number of individuals in the PP, which means the growth is unsustainable.

On the basis of the logistic model, this paper constructs an internal relationship model of product population 2 $\left(\mathrm{PP}_{2}\right)$. It follows that

$$
G_{2}(t)=\frac{\mathrm{d} N_{2}(t)}{\mathrm{d} t}=\alpha_{2} N_{2}\left(1-\frac{N_{2}}{M_{2}}\right),
$$

where $\mathrm{N}_{2}(t)$ represents the number of individuals in the $\mathrm{PP}_{2}$ (product population 2, $\mathrm{PP}_{2}$ ) in period $t$.

This paper should consider the impact of $\mathrm{PP}_{2}$ on $\mathrm{PP}_{1}$. The logistic model can then be modified as follows:

$$
G_{1}(t)=\frac{\mathrm{d} N_{1}(t)}{\mathrm{d} t}=\alpha_{1} N_{1}\left(1-\frac{N_{1}}{M_{1}}+\frac{\beta_{12} N_{2}}{M_{2}}\right)
$$

where $\beta_{12}$ is the influence coefficient of population 2 on population 1. If $\beta_{12}>0$, population 2 has a synergistic effect on population 1. If $\beta_{12}<0$, population 2 has a competitive effect on population 1 .

Once the dependent symbiosis system is formed, the promotion of population 1 means that the size of population 2 will also increase. The scale change of population 2 can be described as follows:

$$
G_{2}(t)=\frac{\mathrm{d} N_{2}(t)}{\mathrm{d} t}=\alpha_{2} N_{2}\left(1-\frac{N_{2}}{M_{2}}+\frac{\beta_{21} N_{1}}{M_{1}}\right)
$$

where $\beta_{21}$ is the influence coefficient of population 1 on population 2. If $\beta_{21}>0$, population 1 has a synergistic effect on population 2. If $\beta_{21}<0$, population 1 has a competitive effect on population 2 .

In the system of $\mathrm{IP}_{1}$ and $\mathrm{IP}_{2}$, the symbiosis mathematical model is

$$
\left\{\begin{array}{l}
G_{1}(t)=\frac{\mathrm{d} N_{1}(t)}{\mathrm{d} t}=\alpha_{1} N_{1}\left(1-\frac{N_{1}}{M_{1}}+\frac{\beta_{12} N_{2}}{M_{2}}\right), \\
G_{2}(t)=\frac{\mathrm{d} N_{2}(t)}{\mathrm{d} t}=\alpha_{2} N_{2}\left(1-\frac{N_{2}}{M_{2}}+\frac{\beta_{21} N_{1}}{M_{1}}\right) .
\end{array}\right.
$$

Of them, $1>\beta_{12}>0,1>\beta_{21}>0 . \beta_{12}$ is the contribution of population 2 to population 1 , which means that the resources that population 2 supplies to population 1 are $\beta_{12}$ times the resources that population 2 supplies itself with. The dependent and independent conditions then establish $1>\beta_{12}>0$. Similarly, $1>\beta_{12}>0$.

The stability analysis of the equilibrium point will now be used to discuss the symbiosis stability of populations 1 and 2 . When they both reach a symbiotic stable state, the differential equations can be expressed as

$$
\left\{\begin{array}{l}
f_{1}\left(N_{1}, N_{2}\right) \equiv \frac{\mathrm{d} N_{1}(t)}{\mathrm{d} t}=\alpha_{1} N_{1}\left(1-\frac{N_{1}}{M_{1}}+\frac{\beta_{12} N_{2}}{M_{2}}\right)=0, \\
f_{2}\left(N_{1}, N_{2}\right) \equiv \frac{\mathrm{d} N_{2}(t)}{\mathrm{d} t}=\alpha_{2} N_{2}\left(1-\frac{N_{2}}{M_{2}}+\frac{\beta_{21} N_{1}}{M_{1}}\right)=0 .
\end{array}\right.
$$

Solving the equations can obtain the equilibrium point of the symbiotic relationship between the two PPs:

$$
P_{1}(0,0), P_{2}\left(N_{1}, 0\right), P_{3}\left(0, N_{2}\right), P_{4}\left(\frac{M_{1}\left(1+\beta_{12}\right)}{1-\beta_{12} \beta_{21}}, \frac{M_{2}\left(1+\beta_{21}\right)}{1-\beta_{12} \beta_{21}}\right) \text {. }
$$

The interdependence of the two populations means that the population size cannot be zero, and so points $P_{1}, P_{2}$, and $P_{3}$ are discarded. $P_{4}$ point, respectively, corresponds to the scale of populations 1 and 2 . Besides, the conditions for $P_{4}$ to be meaningful are

$$
\left\{\begin{array}{l}
\frac{M_{1}\left(1+\beta_{12}\right)}{1-\beta_{12} \beta_{21}}>0 \\
\frac{M_{2}\left(1+\beta_{21}\right)}{1-\beta_{12} \beta_{21}}>0
\end{array}\right.
$$

Only the nonnegative solution can be obtained by solving the preceding equations. The equilibrium point is $\left(M_{1}\left(1+\beta_{12}\right) / 1-\beta_{12} \beta_{21}, M_{2}\left(1+\beta_{21}\right) / 1-\beta_{12} \beta_{21}\right)$. It represents the equilibrium state of resources occupied by $\mathrm{PP}_{1}$ and $\mathrm{PP}_{2}$.

3.3. Model Explained with a Real-Life Scenario. This article takes BYD's new energy vehicle innovation and development as an example to illustrate the practical significance of the above model. BYD Co. Ltd. is a Chinese manufacturer of automobiles and rechargeable batteries based in Shenzhen, Guangdong province. It has two major subsidiaries, BYD Automobile and BYD Electronic. BYD has grown to become a major manufacturer of rechargeable batteries, most notably mobile phone batteries. It was founded in February 1995 and listed on the Hong Kong Stock Exchange on July 31, 2002. A year after the 2002 acquisition of Tsinchuan Automobile Co. Ltd., BYD Automobile Co. Ltd. was born. The market value of BYD Auto is now among the best in the world. Seeking to utilize BYD battery production resources, in addition to gasoline-powered models, BYD sells a full hybrid, the F3DM, and all-electric E6 cars and K9 buses. This paper uses Figure 1 to illustrate the relationship and evolution of BYD's product populations.

As shown in Figure 1, the evolution path of BYD's product population relationship can be found. BYD's battery business and automobile business can be regarded as two related product groups. These two product groups share various resources of BYD, and at this time there is a competitive relationship between them. At the same time, there is a mutually beneficial relationship between the battery product population and the automobile product population. The battery business unit can provide 


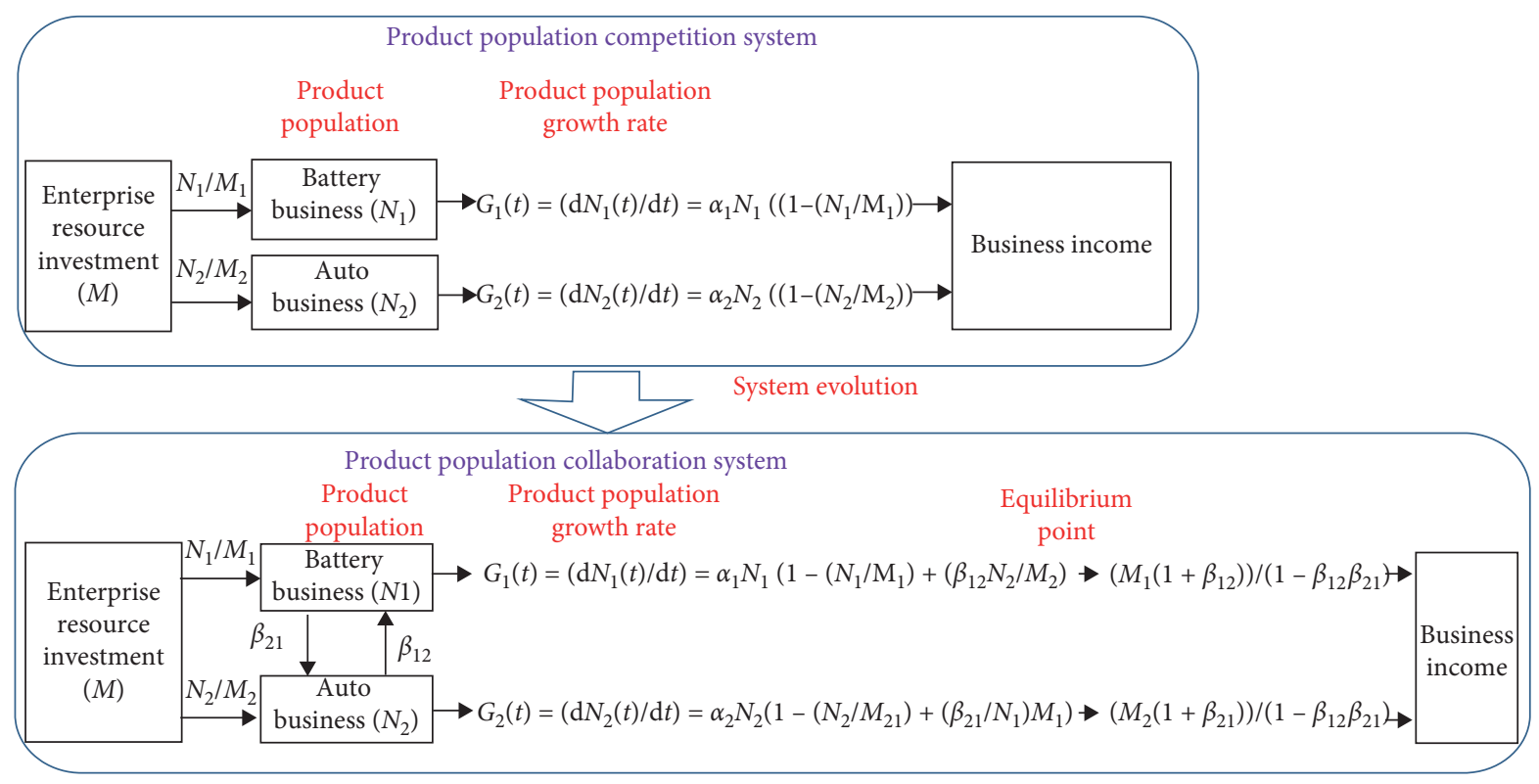

Figure 1: Relationship and evolution of BYD's product populations.

rechargeable batteries to the new energy vehicle business while expanding its own sales. Compared with other competitors, the new energy vehicle business has an advantage in the supply chain. If the company can handle the relationship between the two product groups, it can make the two product groups form a synergistic relationship. The key to the collaborative development of product populations lies in product portfolio design and resource allocation. Product portfolio design and resource allocation influence each other. From the perspective of resource allocation, there is an equilibrium point of combination scale between product populations. At this equilibrium point, the resources allocated to each product group are sufficient, and a synergistic effect is formed between the groups to maximize the benefits of the entire company.

\section{Output Oriented Population Size Optimization Model}

Objective programming is an effective method that can be used to solve the multiobjective programming problem. Its basic idea is to determine a desired value (objective or ideal value) that can be used for each objective function of the multiobjective programming problem. However, the limitations imposed by various conditions mean these objective values are often impossible to achieve. Positive or negative deviation variables are therefore introduced into each objective function to represent a situation where the objective value is either exceeded or not attained. The objective's priority and weighting coefficient are introduced so that the importance of each objective can be distinguished. Constraint equations are then established for all objective functions. On the basis of this new set of constraints, a scheme to minimize the combination deviation is obtained. The foundations of the objective programming model are simple and easy to understand, and the model and its hypothesis are consistent with reality. When compared with other methods, the objective programming method is found to be more convenient, effective, and flexible. It is also more applicable to multiobjective problems.

4.1. Multichoice Goal Programming. In recent years, MCGP (multichoice goal programming) has been widely used to resolve many practical decision-making problems [20]. Chang et al. integrate MCGP and fuzzy mathematics methods and apply them to the different strategic directions of acrylic plate manufacturers [21]. They consider the multiobjective expectation level and fuzzy relationship and thereby help decision-makers select the best supplier. Lee et al. solved the problem of engineering technology selection in product design by a combining MCGP model [22]. Chen et al. propose a three-layer MCGP method that will help forest managers obtain appropriate solutions for forest resource allocation [23]. Chang's MCGP method is described as follows [24]: 


$$
\begin{aligned}
& \text { Objective function: } \operatorname{Min} \sum_{i=1}^{n}\left(d_{i}^{+}+d_{i}^{-}\right)+\sum_{i=1}^{n}\left(e_{i}^{+}+e_{i}^{-}\right), \\
& \text {Constraints: }\left\{\begin{array}{l}
f_{i}(x)-d_{i}^{+}+d_{i}^{-}=g_{i}, \quad i=1,2, \cdots, n, \\
x \in X=\left\{x_{1}, x_{2}, \cdots, x_{m}\right\} \\
g_{i}-e_{i}^{+}+e_{i}^{-}=g_{i, \max }, \quad i=1,2, \cdots, n, \\
g_{i, \min } \leq g_{i} \leq g_{i, \max }, \quad i=1,2, \cdots, n, \\
d_{i}^{+}, d_{i}^{-}, e_{i}^{+}, e_{i}^{-} \geq 0, \quad i=1,2, \cdots, n, \\
X \in F, \quad(F \text { is the set of feasible solutions }) .
\end{array}\right.
\end{aligned}
$$

Here, $d_{i}^{+}, d_{i}^{-}$indicates the value of the $i$ th goal that is close to but does not reach the goal's expected value. $f_{i}(x)$ is the objective function of the $i$ th objective. $X$ is the decision variable, which represents $m$ alternatives $\left(x_{1}, x_{2}, \cdots, x_{m}\right) \cdot g_{i}$ is the expected level for the $i$ th goal. $e_{i}^{+}$and $e_{i}^{-}$are close to positive and negative deviation variables of $\left|g_{i}-g_{i, \max }\right|$. $g_{i, \min }$ and $g_{i, \max }$ are the lower and upper limits of the target for $g_{i}$.

MCGP 9 is a linear form of objective programming, which can be solved by some common linear programming software. Once the objective function is minimized, it can be infinitely close to the objective value. The minimization of the objective function can also enable the objective value to infinitely approach the upper boundary of the objective. Equation (9) can be solved by linear programming, and optimization can be performed by linear programming software. For model performance analysis, see Table 1.

\subsection{Logistic Multichoice Goal Programming Optimization.}

Two main advantages are produced when the logistic model is applied to product portfolio optimization. Resource constraint is the primary constraint of product portfolio optimization. The construction principle of the logistic model is also based on resource constraints in the population living environment. The application of the logistic model to product portfolio optimization can effectively ensure the constraints of resource finiteness. The Internal logistic model can effectively describe the growth dynamics characteristics of product populations. The logistic model between product populations can effectively describe the growth dynamics characteristics under the influence of product population interaction. Products need to find the equilibrium point of output. The equilibrium points are conducive to the common development of the two product populations. The equilibrium points are represented by $M_{1}\left(1+\beta_{12}\right) / 1-\beta_{12} \beta_{21}, M_{2}\left(1+\beta_{21}\right) / 1-\beta_{12} \beta_{21}$.
The optimization results of the product portfolio are reflected in the product quantity and structure. Each product has its own life cycle, and a company cannot produce just one product. The product portfolio must also contain more than one product. The synergy between product groups can be realized by the two constraints of mutual benefit coefficient and product structure. The mutual benefit coefficient is expressed by $\beta_{12}, \beta_{21}$, and the product's structure index is expressed by $M_{1}\left(1+\beta_{12}\right) / M_{2}\left(1+\beta_{21}\right)$.

Once the symbiotic relationship is taken into account, some new constraints need to be added to model (9):

$$
\left\{\begin{array}{l}
x_{1}=\frac{M_{1}\left(1+\beta_{12}\right)}{1-\beta_{12} \cdot \beta_{21}} \\
x_{2}=\frac{M_{2}\left(1+\beta_{21}\right)}{1-\beta_{12} \cdot \beta_{21}} \\
\frac{x_{1}}{x_{2}}=\frac{M_{1}\left(1+\beta_{12}\right)}{M_{2}\left(1+\beta_{21}\right)} \\
0.1<\beta_{12}<1 \\
0.1<\beta_{21}<1
\end{array}\right.
$$

where $M_{1}\left(1+\beta_{12}\right) / 1-\beta_{12} \beta_{21}$ is the equilibrium point that represents the equilibrium state of resources occupied by $\mathrm{PP}_{1} . M_{2}\left(1+\beta_{21}\right) / 1-\beta_{12} \beta_{21}$ is the equilibrium point that represents the equilibrium state of resources occupied by the $\mathrm{PP}_{2}$. $M_{1}\left(1+\beta_{12}\right) / M_{2}\left(1+\beta_{21}\right)$ is the ratio constraint between $\mathrm{PP}_{1}$ and $\mathrm{PP}_{2}$, which can ensure the synergistic relationship between $\mathrm{PP}_{1}$ and $\mathrm{PP}_{2}$ in the optimization operation. Set $\beta_{12}>0.1, \beta_{21}>0.1$ to ensure the distinctiveness of collaborative activities. 
Embed the logistic dynamics model and the symbiotic population equilibrium point as constraints in the MCGP model, and then obtain the logistic-MCGP model:

$$
\begin{aligned}
& \text { objective function: } \operatorname{Min} \sum_{i=1}^{n}\left(d_{i}^{+}+d_{i}^{-}\right)+\sum_{i=1}^{n}\left(e_{i}^{+}+e_{i}^{-}\right), \\
& \qquad\left\{\begin{array}{l}
f_{i}(x)-d_{i}^{+}+d_{i}^{-}=g_{i}, \quad i=1,2, \cdots, n, \\
x \in X=\left\{x_{1}, x_{2}, \cdots, x_{m}\right\}, \\
g_{i}-e_{i}^{+}+e_{i}^{-}=g_{i, \max }, \quad i=1,2, \cdots, n, \\
g_{i, \min } \leq g_{i} \leq g_{i, \max }, \quad i=1,2, \cdots, n, \\
d_{i}^{+}, d_{i}^{-}, e_{i}^{+}, e_{i}^{-} \geq 0, \quad i=1,2, \cdots, n, \\
X \in F,(F \text { is the set of feasible solutions }), \\
X_{1}, M_{1}\left(1+\beta_{12}\right) \\
x_{1}=\frac{M_{12} \beta_{21}}{1-\beta_{1}} \\
x_{2}=\frac{M_{2}\left(1+\beta_{21}\right)}{M_{2}\left(1+\beta_{21}\right)}, \\
x_{2}=\beta_{12}<1,0.1<\beta_{21}<1 .
\end{array}\right.
\end{aligned}
$$

Logistic-MCGP model 11 retains the operational characteristics of the MCGP model and exhibits two new features: (1) the logistic-MCGP model reflects the resource constraint principle of traditional product portfolio research; (2) the model also reflects the synergistic relationship between products in the product portfolio and effectively utilizes resource constraints and Product Population Growth Theory. Equation (11) can be solved by linear programming, and optimization can be performed by linear programming software. For model performance analysis, see Table 1.

\section{An Example}

In this section, an example is given to illustrate the difference between the optimization results of logistic-MCGP and MCGP models. The comparative analysis of model optimization results shows that logistic-MCGP model can take into account resource constraints, product collaboration, and output maximization. Logistic-MCGP model shows good performance in the aspects of operation complexity, operation time, sensitivity analysis, and collaborative entropy evaluation.
5.1. The Relationship between Sample Data and Variables. The company produces two related product populations $\left(\mathrm{PP}_{1}\right.$ and $\left.\mathrm{PP}_{2}\right)$, and there is a synergistic effect between them both. Variable interpretation and data selection are as follows:

(1) $P_{1}$ : population scale of $\mathrm{PP}_{1}$ (sales of $\mathrm{PP}_{1}$, unit: number)

(2) $P_{2}$ : population scale of $\mathrm{PP}_{2}$ (sales of $\mathrm{PP}_{2}$, unit: number)

(3) $C_{1}$ : investment for $P_{1}$ (unit: $1000 \$$ )

(4) $C_{2}$ : investment for $P_{2}$ (unit: $1000 \$$ )

(5) $O_{1}$ : output of $P_{1}$ (expressed by the profit of $P_{1}$, unit: $\$)$

(6) $\mathrm{O}_{2}$ : output of $P_{2}$ (expressed by the profit of $P_{2}$, unit: $\$)$

(7) CT: total investment $\left(\mathrm{CT}=C_{1}+C_{2}\right.$, unit: $\left.1000 \$\right)$

(8) $O_{T}$ : total output $\left(O_{T}=O_{1}+O_{2}\right.$, unit: $\left.\$\right)$

(9) $M_{1}$ : maximum population scale for $\mathrm{PP}_{1}$ (invest the entire budget on $P_{1}$ )

(10) $M_{2}$ : maximum population scale for $\mathrm{PP}_{2}$ (invest the entire budget on $P_{2}$ ) 
TABLE 1: Relative performance of MCGP/(9) and logistic-MCGP/ (11) (CPU time) (hh:mm:ss).

\begin{tabular}{lcc}
\hline Year & MCGP/(9) & Logistic-MCGP/(11) \\
\hline 12 & $00: 00: 00$ & $00: 00: 00$ \\
11 & $00: 00: 00$ & $00: 00: 00$ \\
10 & $00: 00: 00$ & $00: 00: 00$ \\
9 & $00: 00: 00$ & $00: 00: 00$ \\
8 & $00: 00: 00$ & $00: 00: 00$ \\
7 & $00: 00: 00$ & $00: 00: 00$ \\
6 & $00: 00: 00$ & $00: 00: 00$ \\
5 & $00: 00: 00$ & $00: 00: 00$ \\
4 & $00: 00: 00$ & $00: 00: 00$ \\
3 & $00: 00: 00$ & $00: 00: 00$ \\
2 & $00: 00: 00$ & $00: 00: 00$ \\
1 & $00: 00: 00$ & $00: 00: 00$ \\
\hline
\end{tabular}

As shown in Table 2, the sample data can be found. Based on the collaborative perspective, this paper can get the interpopulation relationship model (as shown in Figure 2) between $\mathrm{PP}_{1}$ and $\mathrm{PP}_{2}$.

As shown in Figure 2, the relationship model shows the influence path and variable coefficients between symbiotic innovation populations. The small system composed of two populations can be regarded as a niche in a product ecosystem. In this ecosystem, multiple related populations affect each other, and there are also interactive behaviors within the PPs. This kind of mutual influence can be expressed as coordination or competition. The constraints of the total resources in the environment mean that collaboration between or within populations may not necessarily promote product optimization. The total resource variable is set in the model, which fully reflects the resource constraint mechanism.

5.2. Optimization Model Interpretation. In this case, the number of authorized patents is taken as a measure of innovation output. This paper uses the objective solution of MCGP and the solution of the resource-constrained model (equilibrium value) to construct the suitability of population. The related functions and parameters are listed below:

$F_{1}(X)=10 x_{1}+11.5 x_{2}$ (profit goal, the more the better)

$F_{2}(X)=0.1 x_{1}+0.3 x_{2}$ (investment goal, the less the better)

On the basis of MCGP-achievement, this problem can be formulated as

$$
\begin{aligned}
\operatorname{Min} d_{1}^{+} & +d_{1}^{-}+d_{2}^{+}+d_{2}^{-}+e_{1}^{+}+e_{1}^{-}+e_{2}^{+}+e_{2}^{-} ; \\
\text {s.t. } y_{1} & =10 x_{1}+12 x_{2}-d_{1}^{+}+d_{1}^{-} ; \quad \text { for output goal, the more the better, } \\
y_{2} & =5 x_{1}+8 x_{2}-d_{2}^{+}+d_{2}^{-} ; \quad \text { for expenditure goal, the less the better, } \\
y_{1}-e_{1}^{+}+e_{1}^{-} & =O_{T} ; \quad y_{1}<=O_{T} ; \\
y_{2}-e_{2}^{+}+e_{2}^{-} & =E_{T} ; \quad y_{2}<=C_{T} ; \\
d_{1}^{+}> & =0 \\
d_{1}^{-}> & =0 \\
d_{2}^{+}> & =0 \\
d_{2}^{-}> & =0 \\
e_{1}^{+}> & =0 \\
e_{1}^{-}> & =0 \\
e_{2}^{+}> & =0 \\
e_{2}^{-}> & =0 \\
x_{1} & >0 \\
x_{2} & >0
\end{aligned}
$$


TABle 2: Sample data.

\begin{tabular}{|c|c|c|c|c|c|c|c|c|c|c|c|c|}
\hline Year & $P_{1}$ & $C_{1}$ & $O_{1}$ & $M_{1}$ & $P_{2}$ & $C_{2}$ & $\mathrm{O}_{2}$ & $M_{2}$ & Profit target & Investment budget & $O_{T}$ & $C_{T}$ \\
\hline 12 & 18,000 & 1800 & 180,000 & 18,010 & 1100 & 330 & 12,650 & 6003 & 188,031 & 1801 & 192,650 & 2130 \\
\hline 11 & 14,000 & 1400 & 140,000 & 16,530 & 1000 & 300 & 11,500 & 5510 & 146,809 & 1653 & 151,500 & 1700 \\
\hline 10 & 12,000 & 1200 & 120,000 & 14,870 & 940 & 282 & 10,810 & 4957 & 186,725 & 1487 & 130,810 & 1482 \\
\hline 9 & 11,000 & 1100 & 110,000 & 12,880 & 900 & 270 & 10,350 & 4293 & 198,582 & 1288 & 120,350 & 1370 \\
\hline 8 & 7700 & 770 & 77,000 & 10,720 & 800 & 240 & 9200 & 3573 & 128,325 & 1072 & 86,200 & 1010 \\
\hline 7 & 2200 & 220 & 22,000 & 8580 & 700 & 210 & 8050 & 2860 & 78,507 & 858 & 30,050 & 430 \\
\hline 6 & 2100 & 210 & 21,000 & 7170 & 700 & 210 & 8050 & 2390 & 50,594 & 717 & 29,050 & 420 \\
\hline 5 & 2500 & 250 & 25,000 & 7970 & 690 & 207 & 7935 & 2657 & 26,354 & 797 & 32,935 & 457 \\
\hline 4 & 2200 & 220 & 22,000 & 6860 & 630 & 189 & 7245 & 2287 & 16,439 & 686 & 29,245 & 409 \\
\hline 3 & 1800 & 180 & 18,000 & 6910 & 660 & 198 & 7590 & 2303 & 9435 & 691 & 25,590 & 378 \\
\hline 2 & 1700 & 170 & 17,000 & 5930 & 700 & 210 & 8050 & 1977 & 6514 & 593 & 25,050 & 380 \\
\hline 1 & 1500 & 150 & 15,000 & 5190 & 710 & 213 & 8165 & 1730 & 5439 & 519 & 23,165 & 363 \\
\hline
\end{tabular}

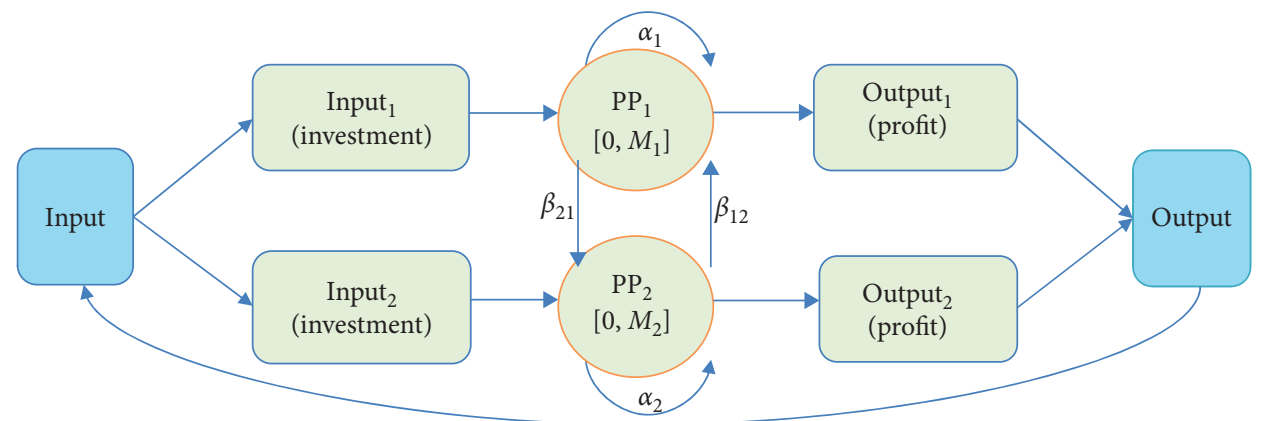

Figure 2: Interpopulation model of $\mathrm{PP}_{1}, \mathrm{PP}_{2}$.

After the symbiotic relationship is considered, new constraints need to be added to the preceding model:

s.t.

$x_{1}=\frac{M_{1}\left(1+\beta_{12}\right)}{1-\beta_{12} \cdot \beta_{21}} ; \quad$ equilibrium value for $\mathrm{PP}_{1}$,

$x_{2}=\frac{M_{2}\left(1+\beta_{21}\right)}{1-\beta_{12} \cdot \beta_{21}} ; \quad$ equilibrium value for $\mathrm{PP}_{2}$,

$0.1<\beta_{12}<1 ; \quad$ for bound of $\beta_{12}$,

$0.1<\beta_{21}<1 ; \quad$ for bound of $\beta_{21}$,

$\frac{x_{1}}{x_{2}}=\frac{M_{1}\left(1+\beta_{12}\right)}{M_{2}\left(1+\beta_{21}\right)} ; \quad$ ratio constraint between $\mathrm{PP}_{1}$ and $\mathrm{PP}_{2}$.

Set $\beta_{12}>0.1, \beta_{21}>0.1$ to ensure the distinctiveness of collaborative activities. The problem is solved using LINGO software [25], as shown in Tables 3 and 4 and Figures 3 and $4 . \mathrm{MP}_{1}$ is the solution of MCGP model for the population scale of $\mathrm{PP}_{1}$ (sales of $\mathrm{PP}_{1}$, unit: number). $\mathrm{MP}_{2}$ is the solution of MCGP model for the population scale of $\mathrm{PP}_{2}$ (sales of $\mathrm{PP}_{2}$, unit: number)

As shown in Table 3, Product 2 has significant advantages in Years 1-5. After Year 8, Product 1 shows significant advantages. Irrespective of the collaboration between the two products, the investment can be tilted towards superior products. The total outputs of the sample and MCGP in the twelve years are 876,595 (unit: $1000 \$$ ) and 1,035,677 (unit: 1000 \$). The optimized result of the MCGP model can create more profits.

The MCGP model can optimize the product mix from the perspective of input and output. This is an effective efficiency improvement measure in the short term. When looking at different product portfolios in isolation, the MCGP model has always been an effective method. There are some extreme values in the optimization results of the MCGP model, such as 0 values. This is a relatively idealized data. In actual production system, a certain product cannot be completely stopped at will. The optimization results of the MCGP model differ greatly from the original data. If the production adjustment is carried out completely according to the optimization results of the MCGP model, it will bring about greater changes to the production system. The requirements for flexibility of the production system are relatively high.

As shown in Figure 3, $P_{1}$ and $\mathrm{MP}_{1}$ follow a similar trend. Product 1 holds a dominant position in the product portfolio. Both the sample observation and optimized data show similar trends. After Year 7, the scale of $P_{1}$ increases rapidly, and this shows that the organizational environment can promote the rapid growth of $P_{1}$. There is a difference between the two values. The development scale of $P_{1}$ does not conform to the standard set by the MCGP model. The $P_{1}$ scale does not meet the optimization goal under the 
TABLE 3: Solution of MCGP model.

\begin{tabular}{lcccccccccc}
\hline Year & $\mathrm{MP}_{1}$ & $C_{1}$ & $O_{1}$ & $M_{1}$ & $\mathrm{MP}_{2}$ & $C_{2}$ & $\mathrm{O}_{2}$ & $M_{2}$ & $O_{T}$ \\
\hline 12 & 18,803 & 1880 & 188,030 & 18,010 & 0 & 0 & 0 & 6003 & 188,030 & 1880 \\
11 & 13,531 & 1353 & 135,310 & 16,530 & 999 & 300 & 11,489 & 5510 & 146,799 & 1653 \\
10 & 18,672 & 1867 & 186,720 & 14,870 & 0 & 0 & 0 & 4957 & 186,720 & 1867 \\
9 & 19,858 & 1986 & 198,580 & 12,880 & 0 & 0 & 0 & 4293 & 198,580 & 1986 \\
8 & 12,832 & 1283 & 128,320 & 10,720 & 0 & 0 & 0 & 3573 & 128,320 & 1283 \\
7 & 7397 & 740 & 73,970 & 8580 & 394 & 118 & 4531 & 2860 & 78,501 & 858 \\
6 & 3147 & 315 & 31,470 & 7170 & 1140 & 342 & 13,110 & 2390 & 44,580 & 657 \\
5 & 0 & 0 & 0 & 7970 & 2291 & 687 & 26,347 & 2657 & 26,347 \\
4 & 0 & 0 & 0 & 6860 & 1429 & 429 & 16,434 & 2287 & 16,434 \\
3 & 0 & 0 & 0 & 6910 & 820 & 246 & 9430 & 2303 & 9430 \\
2 & 0 & 0 & 0 & 5930 & 566 & 170 & 6509 & 1977 & 6509 & 246 \\
1 & 0 & 0 & 0 & 5190 & 472 & 142 & 5428 & 1730 & 5428 \\
\hline
\end{tabular}

TABLE 4: Solution of logistic-MCGP model.

\begin{tabular}{lcccccccccc}
\hline Year & $\mathrm{LMP}_{1}$ & $C_{1}$ & $O_{1}$ & $M_{1}$ & $\mathrm{LMP}_{2}$ & $C_{2}$ & $O_{2}$ & $M_{2}$ & $O_{T}$ & $C_{T}$ \\
\hline 12 & 13,592 & 1359 & 135,920 & 18,010 & 4530 & 1359 & 52,095 & 6003 & 188,015 & 2718 \\
11 & 10,612 & 1061 & 106,120 & 16,530 & 3537 & 1061 & 40,676 & 5510 & 146,796 & 2122 \\
10 & 13,497 & 1350 & 134,970 & 14,870 & 4499 & 1350 & 51,739 & 4957 & 186,709 & 2699 \\
9 & 14,370 & 1437 & 143,700 & 12,880 & 4771 & 1431 & 54,867 & 4293 & 198,567 & 2868 \\
8 & 9276 & 928 & 92,760 & 10,720 & 3091 & 927 & 35,547 & 3573 & 128,307 & 1855 \\
7 & 5675 & 568 & 56,750 & 8580 & 1891 & 567 & 21,747 & 2860 & 78,497 & 1135 \\
6 & 3657 & 366 & 36,570 & 7170 & 1219 & 366 & 14,019 & 2390 & 50,589 & 731 \\
5 & 1905 & 191 & 19,050 & 7970 & 635 & 191 & 7303 & 2657 & 26,353 & 381 \\
4 & 1180 & 119 & 11,880 & 6860 & 396 & 119 & 4554 & 2287 & 16,434 \\
3 & 682 & 68 & 6820 & 6910 & 227 & 68 & 2611 & 2303 & 9431 \\
2 & 470 & 47 & 4700 & 5930 & 156 & 47 & 1794 & 1977 & 6494 \\
1 & 393 & 39 & 3930 & 5190 & 131 & 39 & 1507 & 1730 & 5437 \\
\hline
\end{tabular}

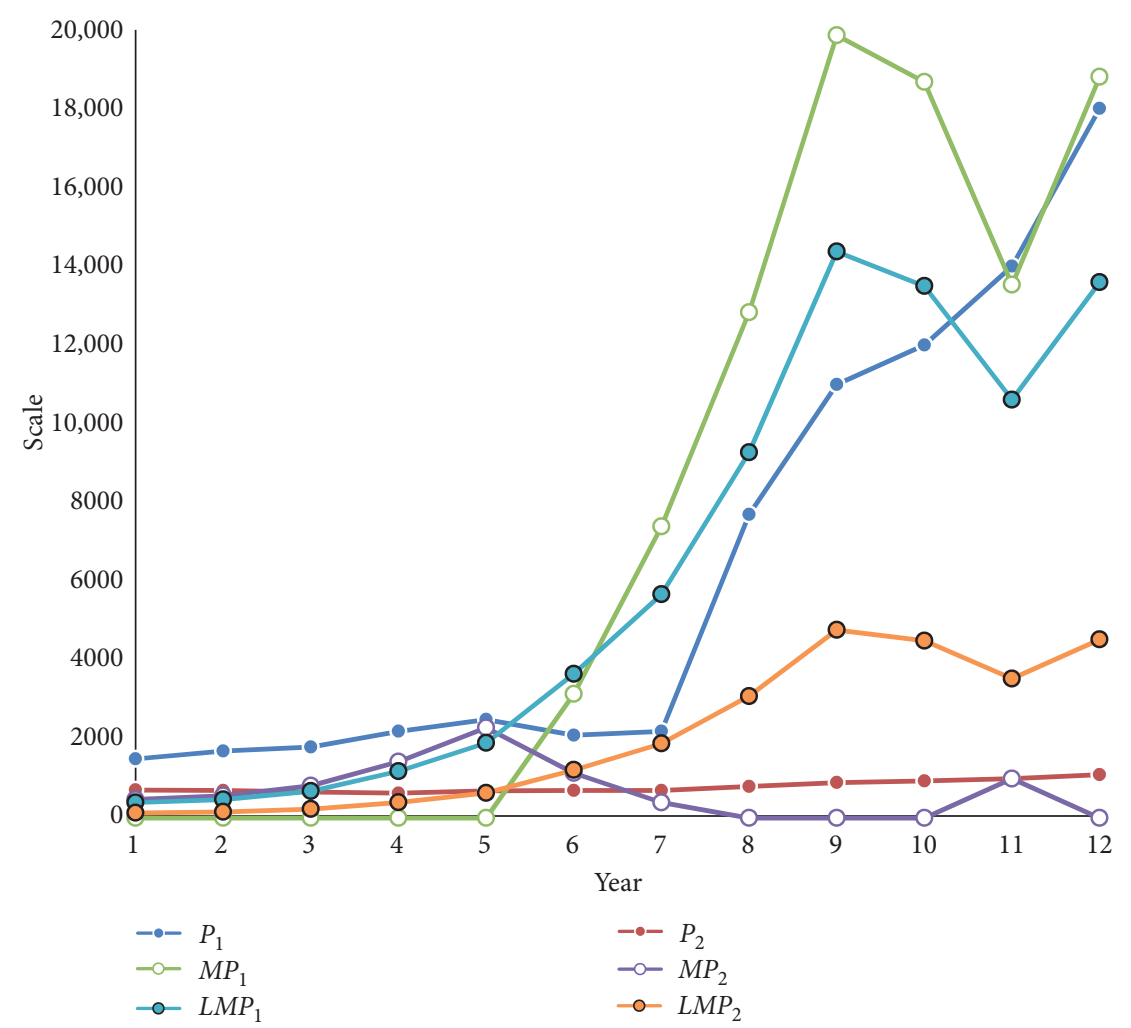

FIGURE 3: Comparison of data between samples, MCGP, and logistic-MCGP. 


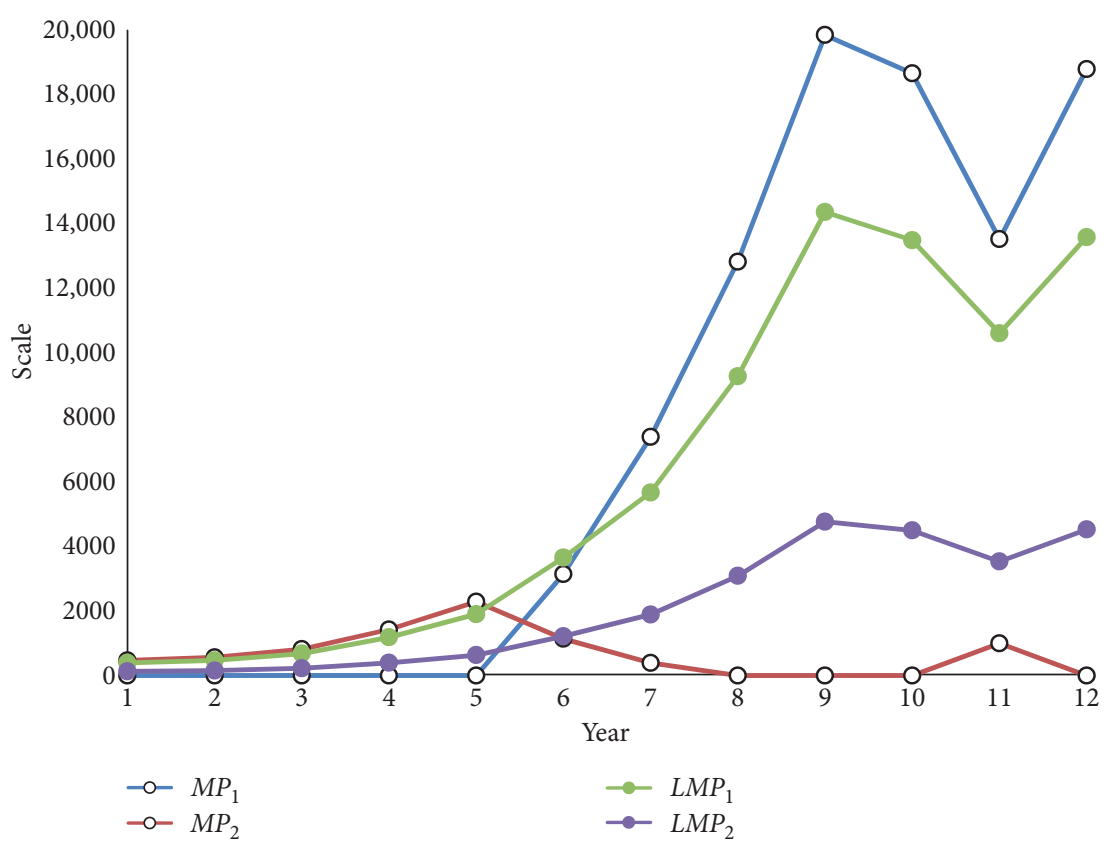

FIgURE 4: Comparison of optimized data between MCGP and logistic-MCGP.

condition of population coordination. In Years 1-5, the optimization value of $\mathrm{MP}_{1}$ is zero. However, the input and output efficiency of $P_{2}$ is higher than that of $P_{1}$ in this period.

$P_{2}$ and $\mathrm{MP}_{2}$ do not follow a similar trend: $\mathrm{MP}_{2}$ shows significant variability and the development scale of $P_{2}$ does not meet the standard set by the MCGP model. $P_{2}$ cannot be adapted to the market environment in the same way as $P_{1} \cdot P_{2}$ does not make full use of resources to help the population develop faster, and this limits the further development of synergy between $P_{1}$ and $P_{2}$.

When compared with the original sample data, the optimization result of the MCGP model shows the following features: (1) higher total return; (2) fuller use of superior products in different periods and an optimized product portfolio that contains superior products.

$\mathrm{LMP}_{1}$ is the solution of logistic-MCGP model for the population scale of $\mathrm{PP}_{1}$ (sales of $\mathrm{PP}_{1}$, unit: number). $\mathrm{LMP}_{2}$ is the solution of logistic-MCGP model for the population scale of $\mathrm{PP}_{2}$ (sales of $\mathrm{PP}_{2}$, unit: number). The optimization results of the logistic-MCGP model are significantly different from the sample data and the optimization results of the MCGP model. Most of the time, the value of $\mathrm{LMP}_{1}$ is between $\mathrm{MP}_{1}$ and $P_{1}$, and the value of $\mathrm{LMP}_{2}$ is significantly higher than that of $\mathrm{MP}_{2}$ and $P_{2}$. The gap between $\mathrm{LMP}_{1}$ and $\mathrm{LMP}_{2}$ is significantly smaller than the gap between MP1 and $\mathrm{MP}_{2}$ and also significantly smaller than the distance between $P_{2}$ and $P_{1}$. The detailed data of the optimization results of the logistic-MCGP model are shown in Table 4.

As shown in Table 4, there is a significant difference between the MCGP and logistic-MCGP optimized values. The total outputs of MCGP and logistic-MCGP in the twelve years are 1,035,677 (unit: 1000 ) and 1,041,625 (unit: 1000 $\$$ ). The optimized result of the logistic-MCGP model can create more profits, and the population optimized scale of
logistic-MCGP is an improvement on MCGP optimization. The collaboration between two products confirms that the investment should not just be tilted towards superior products.

As shown in Figure 4, MP 1 and $\mathrm{LMP}_{1}$ follow a similar trend, although the graphics of $\mathrm{LMP}_{1}$ are smoother. $\mathrm{MP}_{2}$ and $\mathrm{LMP}_{2}$ do not follow a similar trend, and the former shows significant variability. The development scale of MCGP does meet the standard set by the logistic-MCGP model, which is the requirement of the coordinated development of heterogeneous populations. However, the MCGP model does not fully utilize resources in a way that helps the population develop, which limits the further development of synergy between $P_{1}$ and $P_{2}$.

A comparison with the MCGP data shows that the optimization result of the logistic-MCGP model has the following advantages: (1) it has a higher total return; (2) it considers the collaborative development between products and prevents resources being restricted to a certain product; (3) the optimized product fluctuates less during production and is more aligned with the needs of production practice.

The logistic-MCGP model can be regarded as a reconciliation and optimization of the sample data and the MCGP model. There are no extreme values in the optimized data of the logistic-MCGP model. The optimized data of the logisticMCGP model emphasizes the synergy of the two product populations and weakens the difference in the size of the two product populations. The logistic-MCGP model is more in line with the requirements of the actual production system than the MCGP model. The logistic-MCGP model has lower requirements for the flexibility of the production system.

The business ecosystem can organize its own evolution. Cooperation among multiple populations can promote a "win-win" situation for everybody. However, in reality, 
negative cases challenge the self-organized evolution of the innovation ecosystem. This can be attributed to the lack of a detailed and in-depth analysis of the ecosystem's mechanisms. The product portfolio is complex, and its operation is inevitably affected by product interactions. Any discussion of the problem of product portfolio optimization should consider if the logistic-MCGP model can effectively deal with optimization goals such as resource constraints, output maximization, and product synergy.

5.3. Computational Experience. The superiority of the model can be tested by the model operation time. Sample data of each year is formulated as MCGP and logistic-MCGP and then solved by LINGO on a PC (Dell $\left.{ }^{\circledR}\right)$ with CPU (Intel ${ }^{\circledR}$, Core $^{\mathrm{TM}}$, i5-6500) speed of $3.2 \mathrm{GHz}$. The average relative performance of MCGP and that of logistic-MCGP, measured by CPU time, are compared in Table 1.

As shown in Table 1, the two models have no significant difference in computing time, and both can be solved quickly.

5.4. Sensitivity Analysis of $\beta_{12}$ and $\beta_{21}$. Due to space limitations, this article uses the data of the 12th year as an example to illustrate the sensitivity of $\beta_{12}$ and $\beta_{21}$. This paper analyzes the change range of the model optimization results from the situation of $\beta_{12}$ and $\beta_{21}$ with equal increase, single increase, and simultaneous reverse change. The greater the change in the optimization result caused by the change of $\beta$ $\left(\beta_{12}\right.$ or $\left.\beta_{21}\right)$ per unit, the stronger the sensitivity of $\beta$ ( $\beta_{12}$ or $\left.\beta_{21}\right)$ in the model. This paper sets $0.1<\beta\left(\beta_{12}\right.$ and $\left.\beta_{21}\right)<0.5$ in the previous logistic-MCGP model. The reason for setting $\beta<0.5$ is to control the altruistic behavior of a certain product population. The contribution of a certain product population to the related product population should not be higher than the contribution to itself. In order to analyze the sensitivity of $\beta$ ( $\beta_{12}$ and $\left.\beta_{21}\right)$ facilitate, we here set $0<\beta<1$.

As shown in Table $5, \beta\left(\beta_{12}\right.$ and $\left.\beta_{21}\right)$ has significant sensitivity in the model. When $\beta_{12}$ and $\beta_{21}$ change in the same direction and by the same amount, the model optimization result remains unchanged. The asynchronous changing of $\beta_{12}$ and $\beta_{21}$ significantly affects the model optimization results. The optimization result changed even more because of the changing of $\beta_{21}$. Therefore, $\beta_{21}$ is more sensitive than $\beta_{12}$. The changing rate of product population 2 $\left(\Delta \mathrm{LMP}_{2}\right)$ is significantly higher than that of product population $1\left(\Delta \mathrm{LMP}_{1}\right)$. Product population 2 is more sensitive to $\beta$.

5.5. Synergy Evaluation. The paper sought to evaluate the synergy within the product portfolio by constructing an entropy evaluation function between products. There is a contradiction between order and disorder in the management system. The entropy value is used to measure the degree of chaos within the system. When the entropy value is larger, the system is more chaotic. When an enterprise business system that lacks equilibrium constantly exchanges energy, information, and materials with the environment, the negative entropy will continue to increase because of the interaction between various businesses within the enterprise. The order of management business will also increase, form a new orderly structure, and generate a new collaborative process. This paper will use entropy to describe the synergy measurement of cooperation between products.

When the entropy is larger in a closed system, the cooperation between products will be worse [26]. Conversely, when the entropy is smaller, the cooperation will be better [27]. Entropy has been used to measure the uncertainty of a partition [28]. Let $\langle U, \pi\rangle$ be an approximation space, where partition $\pi$ consists of blocks $U_{i}, 1 \leq i \leq k$, each of which has cardinality $n_{i}$. The information entropy $H(\pi)$ of partition $\pi$ is defined by [29]:

$$
H(\pi)=-\sum_{i=1}^{k} \frac{n_{i}}{n} \log \frac{n_{i}}{n}, \quad \text { where } n=\sum_{i=1}^{k} n_{i} .
$$

Based on the research scenarios, this paper subdivides entropy into full collaborative entropy and nonfull collaborative entropy. The optimal data entropy of the logisticMCGP model is full collaborative entropy. The optimized data entropy of MCGP model and sample data is nonfull collaborative entropy. The full synergy entropy and nonfull synergy entropy are defined as follows:

$$
\begin{gathered}
H_{f}(\pi)=-\sum_{i=1}^{k} \frac{n_{i}}{n} \log \frac{n_{i}}{n}, \quad \text { where } n=\sum_{i=1}^{k} n_{i}, \\
H_{n f}(\pi)=-\sum_{i=1}^{k} \frac{n_{i}}{n} \log \frac{n_{i}}{n}, \quad \text { where } n=\sum_{i=1}^{k} n_{i} .
\end{gathered}
$$

In order to evaluate the level of synergy, this paper further proposes the definition of collaborative efficiency $R_{C}$ :

$$
R_{C}=1-\frac{H_{f}(\pi)}{H_{f}(\pi)+H_{n f}(\pi)} .
$$

The full collaborative entropy, nonfull collaborative entropy, and collaborative efficiency of sample, MCGP, and logistic-MCGP are shown in Table 6.

As shown in Table 6 , the mean $R_{C}$ of sample, MCGP model, and logistic-MCGP model is $0.16,0.03$, and 0.81 . The collaborative efficiency of MCGP model optimization results is the lowest. Most of the time, the result of model optimization is in a single product state. This is the main reason for the low collaborative efficiency. The collaborative efficiency of the sample observations is between model MCGP and the logistic-MCGP model. Product 1 is the dominant product in the product portfolio, and it occupies a lot of resources and creates major revenues. There are fewer management activities in a dual-product system with dominant products, and there is a better management order. The collaborative efficiency of the logistic-MCGP model optimization results is higher than the collaborative efficiency of the sample observations. In addition, the full collaborative entropy remains constant. In a product portfolio system, the entropy-invariant state is better than the entropy-increasing state. 


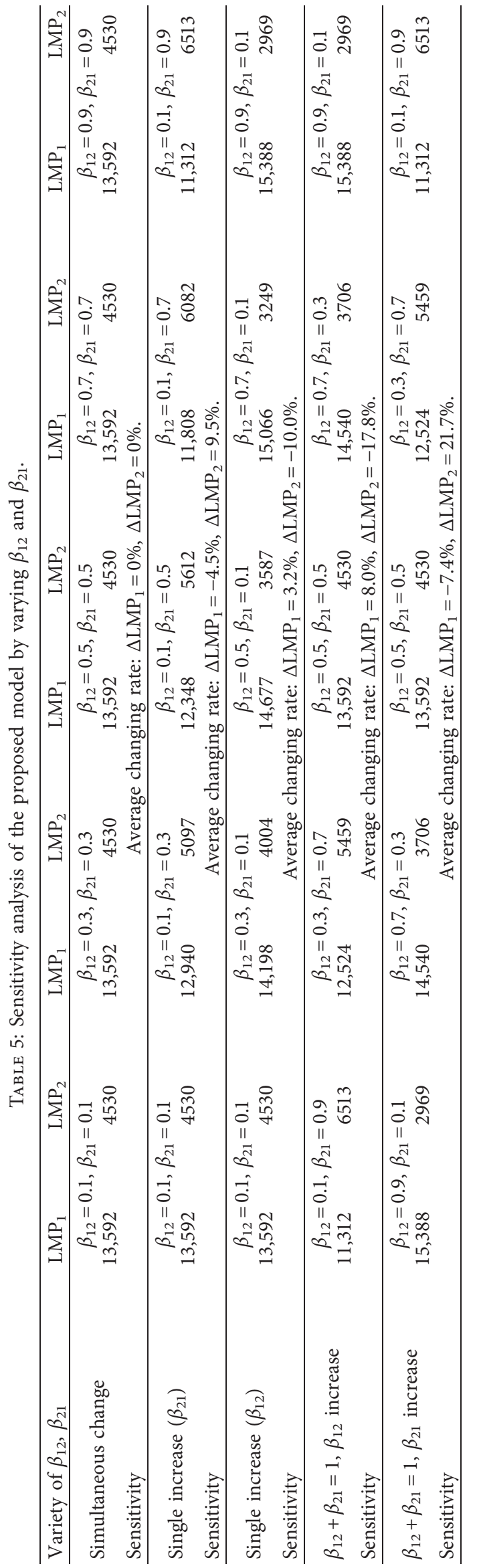


TABLE 6: $H_{f}(\pi), H_{n f}(\pi)$, and $R_{C}$ of sample, MCGP, and logistic-MCGP.

\begin{tabular}{lccccccccccccccc}
\hline Model & Year & 12 & 11 & 10 & 9 & 8 & 7 & 6 & 5 & 4 & 3 & 2 & 1 & Mean \\
\hline \multirow{3}{*}{ Sample } & $H_{f}$ & 1.00 & 1.00 & 1.00 & 1.00 & 1.00 & 1.00 & 1.00 & 1.00 & 1.00 & 1.00 & 1.00 & 1.00 & 1.00 \\
& $H_{n f}$ & 0.10 & 0.11 & 0.11 & 0.12 & 0.14 & 0.24 & 0.24 & 0.23 & 0.23 & 0.25 & 0.26 & 0.27 & 0.19 \\
& $R_{C}$ & 0.09 & 0.10 & 0.10 & 0.11 & 0.12 & 0.19 & 0.19 & 0.19 & 0.19 & 0.20 & 0.21 & 0.21 & 0.16 \\
\hline \multirow{3}{*}{ MCGP } & $H_{f}$ & 1.00 & 1.00 & 1.00 & 1.00 & 1.00 & 1.00 & 1.00 & 1.00 & 1.00 & 1.00 & 1.00 & 1.00 & 1.00 \\
& $H_{n f}$ & 0.00 & 0.11 & 0.00 & 0.00 & 0.00 & 0.09 & 0.25 & 0.00 & 0.00 & 0.00 & 0.00 & 0.00 & 0.04 \\
& $R_{C}$ & 0.00 & 0.10 & 0.00 & 0.00 & 0.00 & 0.08 & 0.20 & 0.00 & 0.00 & 0.00 & 0.00 & 0.00 & 0.03 \\
\hline \multirow{3}{*}{ L-MCGP } & $H_{f}$ & 0.24 & 0.24 & 0.24 & 0.24 & 0.24 & 0.24 & 0.24 & 0.24 & 0.24 & 0.24 & 0.24 & 0.24 & 0.24 \\
& $H_{n f}$ & 1.00 & 1.00 & 1.00 & 1.00 & 1.00 & 1.00 & 1.00 & 1.00 & 1.00 & 1.00 & 1.00 & 1.00 & 1.00 \\
& $R_{C}$ & 0.81 & 0.81 & 0.81 & 0.81 & 0.81 & 0.81 & 0.81 & 0.81 & 0.81 & 0.81 & 0.81 & 0.81 & 0.81 \\
\hline
\end{tabular}

\begin{tabular}{|c|c|c|c|c|c|}
\hline \multicolumn{3}{|c|}{$\begin{array}{c}\text { Stage } 1 \\
\text { Product population growth dynamic }\end{array}$} & \multicolumn{2}{|c|}{$\begin{array}{c}\text { Stage } 2 \\
\text { Multiobjective coordination }\end{array}$} & \multirow{2}{*}{$\begin{array}{c}\text { Stage } 3 \\
\text { Model evaluation } \\
\text { Parameter } \\
\text { sensitivity analysis }\end{array}$} \\
\hline $\begin{array}{c}\text { Population } \\
\text { size }\end{array}$ & $\begin{array}{l}\text { Population } \\
\text { growth }\end{array}$ & $\begin{array}{c}\text { Logistic } \\
\text { model }\end{array}$ & $\begin{array}{c}\text { Two } \\
\text { populations }\end{array}$ & $\begin{array}{l}\text { Logistic-MCGP } \\
\text { model }\end{array}$ & \\
\hline $\begin{array}{c}\text { Input-output } \\
\text { perspective }\end{array}$ & $\begin{array}{c}\text { Multi } \\
\text { objective }\end{array}$ & $\begin{array}{l}\text { MCGP } \\
\text { method }\end{array}$ & $\begin{array}{c}\text { Linear } \\
\text { optimization }\end{array}$ & $\begin{array}{l}\text { Optimization } \\
\text { Results }\end{array}$ & $\begin{array}{c}\text { Population synergy } \\
\text { analysis }\end{array}$ \\
\hline
\end{tabular}

FIgURE 5: Three-stage combination method for product portfolio design.

\section{Discussion}

Population dynamics methods are widely used in product portfolio management. Population dynamics only focuses on the evolution of product scale under resource constraints, and it is difficult to analyze more characteristics of the product portfolio. The MCGP model is also widely used in product decision-making. It is difficult for the MCGP model to reflect the collaborative development requirements between products. Studies that combine the two are relatively rare. The use of the two methods in isolation is not conducive to the collaborative optimization decision-making of the product portfolio, nor is it suitable for real production systems. Therefore, this article provides a three-stage combination method (Figure 5) to make up for the shortcomings of current research.

As shown in Figure 5, a three-stage combination method for product portfolio design was provided by this paper. When actually applying the method constructed in this article, we must first clarify the input-output characteristics of the product mix, be able to construct accurate product input-output equations and their parameters, construct the MCGP model based on the input-output equation, and embed the equilibrium conditions of the population dynamics into the MCGP model to form a multiobjective optimization model (logistic-MCGP model) considering the requirements of coordination. Finally, the optimization results of the model are evaluated through parameter sensitivity analysis and optimization value synergy analysis.

\section{Conclusion}

This paper combined the population dynamic model (logistic model) with the MCGP model to build an analytical path that takes input and output perspectives into account. This paper used optimization values to evaluate population size suitability, which made the evaluation more operable. The results show that combining the two models improves the evaluation of the scale suitability of PPs. In the enterprise product ecosystem, multiple related populations affect each other and there are also interactive behaviors in the PPs. This kind of mutually influential behavior can take the form of coordination or competition. The total resource variable is set in the model, which fully reflects the resource constraint mechanism. The ecosystem can carry out self-organized evolution, and cooperation among or within populations can promote a "win-win" situation. However, in reality, the existence of negative cases challenges the self-organized evolution of the product ecosystem. This is due to a lack of detailed and in-depth analysis of the product ecosystem's mechanisms. This ecosystem is complex, and its operation is inevitably affected by product interactions. The model fully considers the impact of resource constraints on different PPs and then assesses how this might affect the direction of ecosystem evolution.

The innovation subject should, in engaging with management practice, view the innovation activity through an ecosystem lens. When managers make product policies, they should acknowledge the objective process of product development. The enterprise should not blindly encourage the scale expansion of products. In many cases, the enterprise only considers the scale of the PPs but ignores its development structure, and this restricts the product ecosystem's input-output efficiency. Enterprises from across different levels can draw on this paper and formulate policies that will guide the appropriate development of PPs scale. Enterprises, meanwhile, can use its research methods to analyze the competitive situation of different products. Enterprises can adjust their product development strategy and resource allocation by drawing on the results of the competitive situation analysis. The paper used the logistic model of population dynamics and the MCGP method to study the appropriate population scale and structure. In the future, special models and research methods should be developed to study the optimal development scale of PPs. Current 
research does not consider the different life cycles of PPs. The demands for PP resources are changing in the whole life cycle. Future studies should consider the characteristics of the population life cycle and incorporate life cycle factors into their analytical models.

\section{Data Availability}

The experimental data used to support the findings of this study are included within the article.

\section{Conflicts of Interest}

The authors declare that they have no conflicts of interest.

\section{Acknowledgments}

This work was supported by the National Social Science Foundation of China (no. 20BGL203). Thanks are due to Professor Ching-Ter Chang (who proposed the multichoice goal programming method in 2007) of Chang Gung University for his suggestions on this paper.

\section{References}

[1] R. G. Cooper, S. J. Edgett, and E. J. Kleinschmidt, "New products, new solutions: making portfolio management more effective," Journal of Product Innovation Management, vol. 18, no. 1, pp. 52-53, 2001

[2] M. E. Bayou and A. Reinstein, "Analyzing the product-mix decision by using a fuzzy hierarchical model," Managerial Finance, vol. 31, no. 3, pp. 35-48, 2005.

[3] S.-H. Chung, A. H. I. Lee, and W. L. Pearn, "Product mix optimization for semiconductor manufacturing based on AHP and ANP analysis," The International Journal of Advanced Manufacturing Technology, vol. 25, no. 11-12, pp. 1144-1156, 2005.

[4] S. K. Rao, "Re-energizing a product portfolio: case study of a pharmaceutical merger," Journal of Business Strategy, vol. 30, no. 6, pp. 52-62, 2009.

[5] E. M. Goldratt, The Haystack Syndrome: Sifting Information Out of the Data Ocean, North River Press, Croton-onHudson, NY, USA, 1990.

[6] R. Luebbe and B. Finch, "Theory of constraints and linear programming: a comparison," International Journal of Production Research, vol. 30, no. 6, pp. 1471-1478, 1992.

[7] F. Tanhaei and N. Nahavandi, "Algorithm for solving product mix problem in two-constraint resources environment," The International Journal of Advanced Manufacturing Technology, vol. 64, no. 5-8, pp. 1161-1167, 2013.

[8] E. Okutmus, A. Kahveci, and J. Kartašova, "Using theory of constraints for reaching optimal product mix: an application in the furniture sector," Intellectual Economics, vol. 9, pp. 138-149, 2015.

[9] R. Bhattacharyya, A. Chatterjee, and S. Kar, "Uncertainty theory based novel multi-objective optimization technique using embedding theorem with application to R\&D project portfolio selection," Applied Mathematics, vol. 1, no. 3, pp. 189-199, 2010.

[10] R. Bhattacharyya, P. Kumar, and S. Kar, "Fuzzy R\&D portfolio selection of interdependent projects," Computers \& Mathematics with Applications, vol. 62, no. 10, pp. 3857-3870, 2011.
[11] S. Guo, L. Yu, X. Li, and S. Kar, "Fuzzy multi-period portfolio selection with different investment horizons," European Journal of Operational Research, vol. 4, pp. 1-10, 2016.

[12] A. Debnath, J. Roy, S. Kar, and E. K. Zavadskas, "A hybrid MCDM approach for strategic project portfolio selection of agro by-products," Sustainability, vol. 9, no. 1302, pp. 1-33, 2017.

[13] M. B. Kar, S. Majumder, S. Kar, and T. Pal, "Cross-entropy based multi-objective uncertain portfolio selection problem," Journal of Intelligent \& Fuzzy Systems, vol. 32, no. 6, pp. 4467-4483, 2017.

[14] M. B. Kar, S. Kar, S. Guo, X. Li, and S. Majumder, "A new biobjective fuzzy portfolio selection model and its solution through evolutionary algorithms," Soft Computing, vol. 23, no. 12, pp. 4367-4381, 2018.

[15] B. Rober, “"'Determing the appropriate depth and breadth of a firm's product portfolio"' Journal of Marketing Research, vol. 40, no. 2, pp. 39-53, 2003.

[16] G. E. Fruchter, A. Fligler, and R. S. Winer, "Optimal product line design: genetic algorithm approach to mitigate cannibalization," Journal of Optimization Theory and Applications, vol. 131, no. 2, pp. 227-244, 2006.

[17] R. V. Ommering, "Beyong product families: building a product population," Lecture Notes in Computer Science, vol. 1951, pp. 187-198, 2000.

[18] Y. Kazuhiko, M. Yasunari, and Y. Masaru, "Integration of life cycle assessment and population balance model for assessing environmental impacts of product population in social scale case studies for the global scale case studies for the global warming potential of air conditioners in Japan," The International Journal of Life Cycle Assessment, vol. 8, no. 3, pp. 129-136, 2003.

[19] S. Kim, M. Oguchi, A. Yoshida, and A. Terazono, "Estimating the amount of WEEE generated in South Korea by using the population balance model," Waste Management, vol. 33, no. 2, pp. 474-483, 2013.

[20] C.-T. Chang, "Multi-choice goal programming," Omega, vol. 35, no. 4, pp. 389-396, 2007.

[21] C.-T. Chang, C.-Y. Ku, and H.-P. Ho, "Fuzzy multi-choice goal programming for supplier selection," International Journal of Operations Research and Information Systems, vol. 1, no. 3, pp. 28-52, 2010.

[22] A. H. I. Lee, H.-Y. Kang, C.-Y. Yang, and C.-Y. Lin, "An evaluation framework for product planning using FANP, QFD and multi-choice goal programming," International Journal of Production Research, vol. 48, no. 13, pp. 3977-3997, 2010.

[23] Y.-T. Chen, C. Zheng, and C.-T. Chang, "3-level MCGP: an efficient algorithm for MCGP in solving multi-forest management problems," Scandinavian Journal of Forest Research, vol. 26, no. 5, pp. 457-465, 2011.

[24] C.-T. Chang, "Revised multi-choice goal programming," Applied Mathematical Modelling, vol. 32, no. 12, pp. 25872595, 2008.

[25] L. Schrage, LINGO Release 8.0, LINDO System, Inc, Chicago, IL, USA, 2002.

[26] C. E. Shannon, "A mathematical theory of communication," Bell System Technical Journal, vol. 27, no. 3, pp. 379-423, 1948.

[27] I. Düntsch and G. Gediga, "Uncertainty measures of rough set prediction," Artificial Intelligence, vol. 106, no. 1, pp. 109-137, 1998.

[28] M. J. Wierman, "Measuring uncertainty in rough set theory," International Journal of General Systems, vol. 28, no. 4-5, pp. 283-297, 1999. 
[29] Y. Y. Yao, "Probabilistic approaches to rough sets," Expert Systems, vol. 20, no. 5, pp. 287-297, 2003. 